\title{
UM ESTUDO DE GRADIÊNCIA COM O VERBO PASSAR
}

\author{
Geisa Maria Jayme Jordão*
}

Resumo: Este artigo tem por objetivo apresentar uma investigação inicial de construções que se desenvolvem a partir de expressões formadas com o verbo passar, considerando sua diversificada utilização em um cline de gradiência, seguindo uma perspectiva de gramaticalização, que parte de um uso mais concreto até um uso mais abstrato. Este estudo se baseia em teorias do funcionalismo.

Palavras-chave: Funcionalismo; gramaticalização; prototipicidade; construções; gradiência.

Abstract: This paper aims to present an initial investigation of constructions that are developed from expressions formed with the verb passar, considering their diversified use in a cline of gradience, following the perspective of grammaticalization, which parts of a more concrete to a more abstract use. This study is based on the theories of functionalism.

Keywords: Functionalism; grammaticalization; prototypes; constructions; gradience.

\section{Introdução}

O verbo passar apresenta extensa aplicação na língua portuguesa, podendo ser analisado dentro de um cline de gramaticalização, segundo os aspectos semânticos e cognitivos que apresenta dentro de um âmbito comunicativo, considerando também seu aspecto polissêmico.

* Universidade Federal Fluminense. 
Para Bybee (2003), a gramaticalização é a criação de novas construções. Assim, a gramaticalização é fixação de padrões, observando-se que aquilo que se usa mais é o que se regulariza. Busca-se nesta pesquisa construir um cline de gradiência numa perspectiva sincrônica, analisando os dados pesquisados em textos do Corpus D\&G (Niterói, Natal, Rio de Janeiro e Juiz de Fora).

Investiga-se, nesse cline de gradiência, a possível gramaticalização de certas construções, levando em consideração a frequência, a semântica e a variação nesses usos. Para isso, a investigação das construções partiu de usos mais concretos, lexicais, para usos mais abstratos, gramaticais. Este estudo está fundamentado em teorias do funcionalismo, em que uma construção gramatical emerge de uma construção lexical: inicialmente, o vínculo semântico-sintático é maior e, à medida que a construção se gramaticaliza, o sentido torna-se mais abstrato, ou pragmático, ou interpessoal, ou lógico-semântico.

O presente estudo analisa um percurso de gramaticalização do verbo passar, dentro de um cline de gradiência léxico> gramática, que parte de usos mais concretos para usos menos concretos até chegar a usos mais abstratos, entendendo que, nesse processo de gramaticalização, a mudança vai ocorrer na direção do final de um continuum.

\section{Pressupostos teóricos}

\subsection{Funcionalismo}

O termo funcionalismo ganhou força nos Estados Unidos a partir da década de 1970, passando a servir de rótulo para o trabalho de linguistas como Sandra Thompson, Paul Hopper e Talmy Givón, que defendem uma linguística baseada no uso, observando a língua do ponto de vista do contexto linguístico e da situação extralinguística. 
No campo da sintaxe, os funcionalistas consideram mais aceitável a ideia da não-arbitrariedade. A ordem sintática é motivada, e os funcionalistas chamam esta motivação de iconicidade.

Os funcionalistas opõem-se à distinção entre langue e parole. Neste aspecto, o posicionamento funcionalista consiste em dar relevo aos usos sociais, passando a compreendê-los como nível gerador da gramática das línguas.

O que se percebe no funcionalismo norte-americano a partir das pesquisas sobre gramaticalização (HEINE, CLAUDI \& HÜNNEMEYER, 1991; TRAUGOTT \& HEINE, 1991; HOPPER \& TRAUGOTT, 1993) é que se focalizam nos mecanismos que geram a mudança como sendo alicerçados em fatores comunicativos e cognitivos, num viés que reúne as perspectivas sincrônicas e diacrônicas. Assim, pode-se dizer que, neste sentido, o funcionalismo tende a adotar uma concepção pancrônica de mudança.

O funcionalismo apresenta arcabouço teórico ideal para a investigação que se propõe neste artigo, pois favorece a pesquisa de estruturas mais extensas do discurso, como são as construções com o verbo passar.

\subsection{A gradiência e a variação linguística}

Segundo Bybee (2010), todos os tipos de unidades linguísticas apresentam gradiência. Considera-se, nesta pesquisa, uma gradiência nas construções do verbo passar, observando que há uma variação de usos de construções com sentidos mais concretos, como também há construções com sentidos menos concretos. Essas variações e mudanças são necessárias e essenciais para a análise dos dados, devendo-se pensar a língua como afetada pelo uso e com o impacto da experiência no sistema cognitivo. Sendo a língua uma estrutura mental em constante uso e afetada por atividades processuais que mudam, nela podem existir, então, variação e gradiência no mesmo processo.

De acordo com Bybee (2010), os fenômenos estruturais observados na gramática das línguas podem derivar dos processos 
cognitivos do domínio geral, enquanto operam nas múltiplas instâncias do uso linguístico. Logo, fatos sobre uso, processamento cognitivo e mudança linguística são articulados, para que forneçam uma explanação com respeito às propriedades das estruturas linguísticas em observação.

$\mathrm{Na}$ perspectiva teórica funcionalista, a variabilidade é entendida como uma das etapas de mudança cumprida pelas formas linguísticas em sua trajetória de regularização ou convencionalização gramatical, conforme Votre \& Oliveira (2001).

\subsection{A gramaticalização}

Do ponto de vista semântico, a gramaticalização tem sido considerada um processo de progressiva abstração metafórica. Heine (1991) apresenta uma hierarquia nesse processo, utilizando poucas categorias básicas, que devem ser consideradas da esquerda para direita: pessoa $>$ objeto $>$ processo $>$ espaço $>$ tempo $>$ qualidade. A análise parte do mais concreto ao mais abstrato, podendo cada um dos domínios à esquerda ser usado na conceptualização dos domínios mais à direita.

De acordo com Heine (1991), a gramaticalização deve ser vista como o resultado de uma estratégia de resolução de problema, segundo a qual conceitos, que são mais imediatamente acessíveis à experiência humana, são empregados para a expressão de conceitos abstratos, menos acessíveis.

Nos estágios de mudança da gramaticalização, relativos às categorias lexicais, podem ser identificadas fases que caracterizam a mudança do lexical $>$ gramatical ou do [gramatical] > [+gramatical]. Lehmann (1995) apresenta as seguintes fases, no esquema abaixo reproduzido de Gonçalves $e t$ al. (2007): 


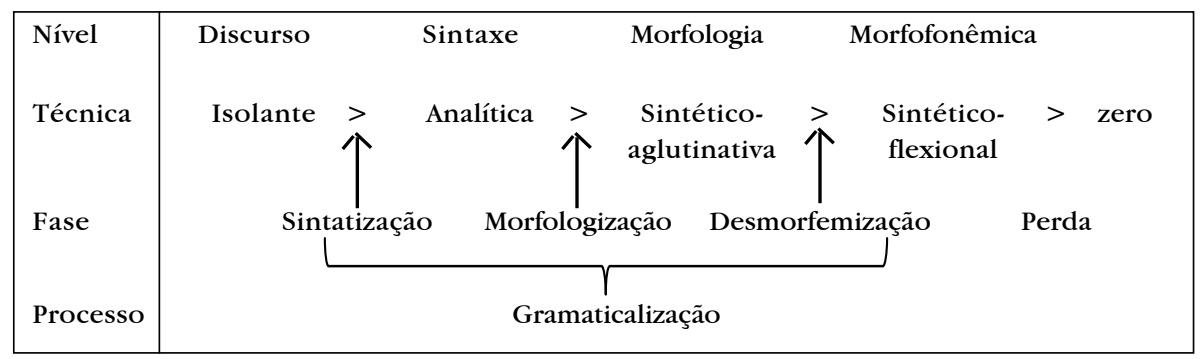

Outra forma de se acompanhar a gramaticalização de um item ou de alguma expressão baseia-se nos seus valores semânticos, aplicáveis a uma esfera mais conceptual. A transferência de um sentido literal para outro figurado e do domínio de conceptualização para outro promove o deslizamento de um sentido mais concreto para um mais abstrato.

Os estudos de Bybee et al. (1994) acerca dos mecanismos que motivam a gramaticalização, como extensão, metáfora, inferência, generalização, harmonia e absorção, serão aprofundados em outro momento. A extensão metafórica de um item ou expressão caracteriza-se por meio de duas propriedades: (i) mudança de um domínio mais concreto para um domínio mais abstrato; e (ii) preservação de algum traço de estrutura relacional original.

\section{Categorização prototípica do verbo passar}

Caracteriza-se a prototipicidade como um modelo de forma que se sustenta, por guardar sua essência nas construções que decorrem desse modelo. O verbo passar, no sentido mais prototípico, está relacionado à movimentação, mudança de lugar e referências temporais. Guardando esses valores semânticos, observa-se uma extensão significativa desses usos nas práticas interacionais. É verbo de $1^{\mathrm{a}}$ conjugação, regular, e segundo o Dicionário Caldas Aulete (1986, v. 4, p. 1436), o verbo passar apresenta as seguintes acepções, entre outras: 
$v$. $t r$ atravessar, percorrer de um lado para outro; transpor: Passar um rio; passar uma ponte. [...] Transportar, conduzir: o barqueiro passou-me para a outra margem do rio. [...] $v$. intr. ser transferido, mudado de lugar (com a preposição $a$ ou para): Assentou-se que a gente passasse aos batéis. [...] Mudar-se ou ser mudado de uma ocupação ou posição moral para outra, de um estado para outro: Um oficial que passou de infantaria para cavalaria. [...] Percorrer um lugar sem se demorar nele; transitar: Passou há pouco pelo Rossio. [...] Desaparecer, acabar, cessar; irse, extinguir-se: Já me passou a dor; deixou passar a ocasião. [...] Esquecer: Porque enfim tudo passa. [...] Ser aprovado em exame: $\mathrm{O}$ aluno passou em matemática. [...] Ser transmitido: A notícia passou de boca em boca. [...] Estar, achar-se (com relação à saúde): Ele nunca passa bem.

Como o verbo passar é bem produtivo na língua, observase que certo membro de uma categoria pode se destacar de outro membro por sua frequência ou por sua flexibilidade em acomodar dados novos. Sendo assim, considera-se que a forma prototípica do verbo passar é a apresentada e referenciada pelos usos determinados no dicionário e nas gramáticas. O verbo passar é usado com frequência como verbo que indica movimento, mudança de lugar e relações temporais em padrões construcionais diferentes, dependendo do contexto.

\section{Metodologia}

Esta pesquisa teve início com a observação de construções com o verbo passar, entendendo construções como expressões formadas por duas ou mais palavras. Por critério de análise, foram selecionadas quarenta ocorrências com o verbo passar do Corpus D\&G (Niterói, Rio de Janeiro, Natal e Juiz de Fora). Após essa seleção, verificou-se a predicação verbal e seus argumentos. $\mathrm{Na}$ sequência, essas construções foram agrupadas, para que se estabelecesse o cline de gradiência. 


\subsection{Análise dos dados}

Parte-se, neste estudo, do uso lexical do verbo passar, verbo pleno, concreto, para o uso mais gramatical, seguindo um cline em que as construções apresentam usos livres e usos mais presos, mais dependentes do contexto. As construções foram analisadas segundo os seguintes critérios: (a) usos mais concretos: como verbo intransitivo, indicando mudança de lugar, espaço físico e movimentação observável; (b) usos menos concretos: como verbo transitivo, numa gradiência de seus complementos;(c) usos em construções em que os complementos estão relacionados ao tempo.

Abaixo estão relacionadas as quarenta ocorrências selecionadas para este artigo e, em seguida, a análise dos dados, seguindo a gradiência espaço $>$ tempo, concreto $>$ abstrato (itálicos nossos):

(1) "Nós ficamos numa sala confortável, no entanto, era uma sala de espera, ou seja, às vezes passava alguém." (D\&G - Niterói - Inf. 2)

(2) "Eu passei e sentei ao lado de um bomem que imediatamente começou a arregalar os olhos para mim..." (D\&G - Niterói - Inf. 11)

(3) "Como ela mora perto da minha tia, esta passou na portaria do prédio e trouxe para mim a parte escrita." (D\&G Niterói - Inf. 8)

(4) "Só que não vi a porta de vidro da varanda e passei direto quebrando o vidro todo...” (D\&G - Niterói - Inf. 18)

(5) “... e ... foi o que ela fez ... ela ... passou pro meu lado... o homem... se acomodou lá...” (D\&G - Natal - Inf. 4)

(6) “... temos que passar por um corredor... onde... onde é obrigatório a passagem..." (D\&G - Natal - Inf. 1)

(7) “... se você for para a cozinha... você tem que passar pela sala...” (D\&G - Natal - Inf. 1)

(8) “... eu estava esperando você passar aqui...” (D\&G - RJ - Inf. 5) 
(9) “... mas o motorista não passou pela direita, então o ônibus passou pela direita e trancou a gente e jogou todo mundo na estrada." (D\&G - Natal - Inf. 1)

(10) “...ele estava se arrumando pra ir ao baile ... no morro... e resolveu passar ... um pouco de perfume ...” (D\&G Natal - Inf. 4)

(11) “...aí:: eu passei o som... testei a aparelhagem toda...” (D\&G - RJ - Inf. 9)

(12) “... e afinar duas varetas passar a linha na ponta da vareta e...” (D\&G - Niterói - Inf. 10)

(13) “... que eles procurem ... passar a matéria...” (D\&G - RJ - Inf. 9

(14) “... o pôr-do-sol... aí passou o medo...” (D\&G - Natal Inf. 4)

(15) “... e passar cola no papel cortar cola e está pronto." (D\&G - Niterói - Inf. 10)

(16) “... e você basta passar óleo de linhaça... ou então até dar uma raspadinha que a tinta sai...” (D\&G - RJ - Inf. 24)

(17) "No final podemos passar verniz para evitar que o grafite se desmanche na tinta..." (D\&G - RJ - Inf. 24)

(18) “... não peguei cheque... não posso te passar cheque... agora só segunda-feira...” (D\&G - Niterói - Inf. 5)

(19) “... depois tinha que passar caneta ... que era um negócio chamado ca/eh:: (canetado)...” (D\&G - Niterói - Inf. 8)

(20) “... depois você passa nanquim por cima.. nanquim de preferência preto...” (D\&G - Juiz de Fora - Inf. 3)

(21) "Passar margarina na forma e colocar os ingredientes na forma..." (D\&G - Natal - Inf. 3)

(22) “... depois veio o cara... passou cloro... tirou o gambá..." (D\&G - Juiz de Fora - Inf. 15) 
(23) “... é... passar vexames... então ele disse que começaram a descer os pratos finos..." (D\&G - Natal - Inf. 4)

(24) "O desenho livre tem uma grande vantagem, pois o desenhista pode passar emoção, uma ideia..." (D\&G Natal - Inf. 1)

(25) “... precisava de sessenta pra entrar... foi ótimo... eu cheguei na casa da minha tia pulando... né? pô... passei... eu consegui..." ( D\&G - Niterói - Inf. 8)

(26) “... aqui no/na escola mesmo... depois passa pros alunos...” (D\&G - Niterói - Inf. 2)

(27) “- Olha, já vou falando que não deu tempo de passar, pois ontem tive que sair e quando vi já eram 16:30 da tarde." (D\&G - Niterói - Inf. 5)

(28) “... e foi seguim né... caminho... só que passou muitos dias nessa caminhada...” (D\&G- Natal - Inf. 3)

(29) “... eh... eu fui passar uns dias em São Paulo.. isso tem::... uns oito anos atrás...” (D\&G - Juiz de Fora - Inf. 2)

(30) “... aí os caras falaram que era para quando ele/quando eles irem embora passar cinco minutos eles saírem..." (D\&G - Niterói - Inf. 10)

(31) “... se um ganhasse uma coisa era todo mundo... pra todo mundo... passou-se o domingo..” (D\&G - Natal - Inf. 3)

(32) “... ele passou seis meses nessa casa e..." (D\&G - Natal Inf. 4)

(33) “...bom... foi passando um ano... um ano e a gente nada de fazer... aí começo/começaram os ensaios da... préestreia...” (D\&G - Niterói - Inf. 6)

(34) “... então a gente já passou uma fase ... trabalhando com... é... material escrito... certo? (D\&G - Natal - Inf. 4)

(35) “... a todo mundo voltou dançando... aí passou mais um tempo briga comeu de novo...” (D\&G - Niterói - Inf. 10) 
(36) “...De repente alguém passou a vida mau, assassinando, roubando: então esse indivíduo de um momento para o outro resolveu se arrepender, e aceitando Cristo está salvo do fogo do inferno." (D\&G - Natal - Inf. 2)

(37) “... porque eu sou uma eterna criança... eu passo a vida inteira levando tudo na brincadeira..." (D\&G - Natal Inf. 2)

(38) “... mas com o passar do tempo ela foi né... gostando dela... foi passando a se acostumar com ela...” (D\&G Natal - Inf. 4)

(39) "Porém com o passar da gravação e com o meu estímulo consegui fazer ela soltar." (D\&G - RJ - entrevistador sobre o Inf. 21)

(40) "Com o passar dos dias a seca voltará como uma peste, destruindo a tudo." (D\&G - Natal - Inf. 3)

Conforme a proposta deste estudo, as construções foram agrupadas de acordo com a semelhança de usos e sentidos e o cline apurado apresenta uma mudança gradual de construções mais concretas em direção a construções mais abstratas, observando que, segundo Lehmann (1989), o uso lexical é mais concreto, é o uso dicionarizado, e o uso gramatical está sujeito às regras da gramática, é mais abstrato ou indexal, isto é, mais pragmático, contextual. Sendo assim, apresenta-se o cline de gradiência da seguinte forma:

1 grupo: (01) a (09) - Consideram-se estas construções com o verbo passar em uso concreto, pois há um sujeito praticando a ação, o movimento de passar indica mudança física de lugar. Verbo intransitivo, pleno, acompanhado de adjuntos adverbiais. Os adjuntos adverbiais que indicam mudança de lugar, de posição, de direção, como estão nas construções, são mais evidentes, observáveis do ponto de vista físico, isso torna as construções mais concretas, para nosso estudo. 
$2^{\circ}$ grupo: (10) a (14) - As construções com o verbo passar apresentam-se mais presas, pois nestes casos o verbo passar é transitivo direto, reclamando um objeto. É menos concreto porque precisa desse objeto, estabelecendo grau de dependência gramatical. Observa-se, também, que em (14) há uma gradiência quanto ao complemento verbal, pois o termo medo é menos concreto em relação aos outros objetos.

$3^{\circ}$ grupo: (15) a (24) - As construções apresentam-se diferentes das do $2^{\circ}$ grupo, visto que os complementos não vêm acompanhados de determinantes, como os artigos definidos ou indefinidos, sugerindo, segundo algumas pesquisas, o início de um processo de gramaticalização, conforme Saraiva (2010).

$4^{\circ}$ grupo: (25) a (27) - Estas construções com o verbo passar são mais dependentes gramaticalmente, pois os objetos não estão expressos, ficando a compreensão presa à interação comunicativa.

$5^{\circ}$ grupo: (28) a (33) - Estes casos apresentam construções temporais. A gradiência foi feita atendendo ao princípio de tempo definido: as construções com tempo determinado são mais concretas do que as que se apresentam no $6^{\circ}$ grupo, que também são construções temporais, mas são expressas de maneira vaga, ou são presas às questões cognitivas, emocionais. Porém, estes usos são menos concretos em relação às construções anteriores.

$6^{\circ}$ grupo: (34) a (40) - Estas construções se apresentam muito subjetivas, presas e abstratas e de usos muito recorrentes nas situações comunicativas. Observa-se que as construções em (38), (39) e (40) “com o passar..." sugerem itens mais presos, mais gramaticais, indicando mudança morfossintática.

Esta análise procurou representar um continnum, em que as construções com o verbo passar, em certas circunstâncias interacionais, apresentam-se numa gradiência de construções lexicais para construções gramaticais e destas para construções mais 
gramaticais. As alterações semânticas podem deixar as construções, que antes eram livres, agora mais presas, mais dependentes do contexto em que se apresentam. Para que se possa visualizar essa gradiência, apresenta-se o Quadro 1 (cline de gradiência), em que se procurou estabelecer uma hierarquia tanto na linha horizontal, quanto na vertical, de acordo com a análise feita.

QUADRO 1

Cline de gradiência do verbo passar

\begin{tabular}{|c|c|c|c|c|c|}
\hline \multicolumn{6}{|c|}{ Valor lexical $>>>$ Valor gramatical } \\
\hline \multicolumn{2}{|c|}{$\begin{array}{c}\text { Usos concretos } \\
\text { lexicais }\end{array}$} & \multicolumn{2}{|c|}{$\begin{array}{c}\text { Usos menos concretos } \\
\text { gramaticais }\end{array}$} & \multicolumn{2}{|c|}{$\begin{array}{l}\text { Psos abstratos } \\
\text { mais gramaticais }\end{array}$} \\
\hline $1^{\circ}$ grupo & $2^{\circ}$ grupo & $3^{\circ}$ grupo & $4^{\circ}$ grupo & $5^{\circ}$ grupo & $6^{\circ}$ grupo \\
\hline (01) & (10) & (15) & (25) & $(28)$ & (34) \\
\hline$(02)$ & (11) & (16) & (26) & (29) & (35) \\
\hline (03) & (12) & (17) & (27) & (30) & (36) \\
\hline$(04)$ & (13) & (18) & & $(31)$ & (37) \\
\hline$(05)$ & (14) & (19) & & $(32)$ & (38) \\
\hline$(06)$ & & (20) & & (33) & (39) \\
\hline$(07)$ & & (21) & & & $(40)$ \\
\hline$(08)$ & & (22) & & & \\
\hline$(09)$ & & (23) & & & \\
\hline & & (24) & & & \\
\hline
\end{tabular}

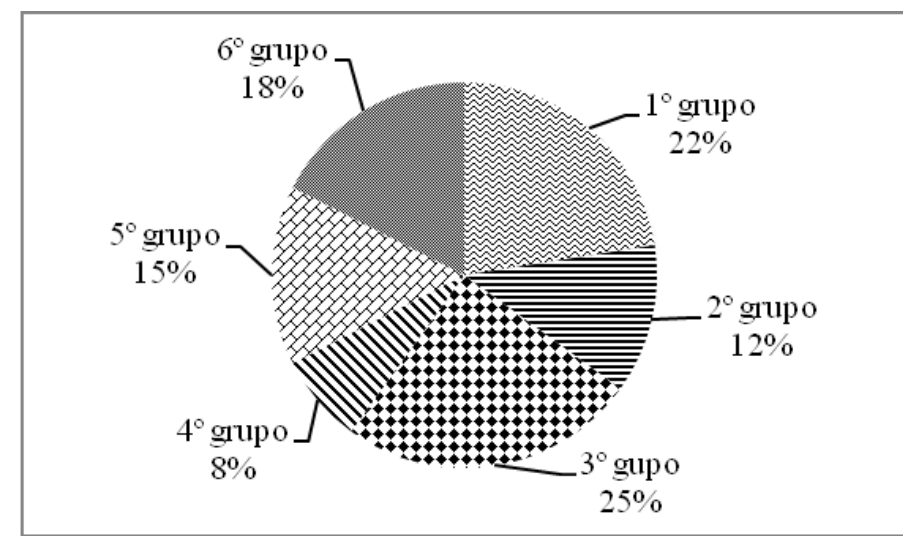

FIGURA 1 - Percentual por amostragem 
Estes referenciais servem de base para maior aprofundamento dessas construções, observando que, para Traugott \& Dasher (2005), há três tendências que se sobrepõem na unidirecionalidade da gramaticalização: (i) descrição de situação externa > descrição de situação interna (avaliativa, perceptual, cognitiva) - ex: concreto $>$ abstrato, físico > mental; (ii) descrição de situação externa ou interna $>$ sentidos baseados em situação textual e metalinguística - ex: desenvolvimento de conectivos e de itens metalinguísticos ou metatextuais; e (iii) sentidos tendem a se tornar mais baseados em crenças, estados e atitudes subjetivas dos emissores na configuração proposicional - ex: tendência dominante, envolve a auto-orientação dos emissores, envolve subjetificação, a que a intersubjetificação está subordinada; não é restrita a um termo específico, mas sim a uma "expressão" em seu contexto interacional de uso.

\section{Considerações finais}

Os estudos de gradiência nos permitem analisar uma expressão em construções que apresentem usos motivados pelas situações interacionais. $\mathrm{O}$ verbo passar é muito produtivo na língua portuguesa, devido ao grande número de acepções que apresenta. Pesquisar esse verbo em construções, dentro de um cline de gradiência, numa perspectiva sincrônica, é tentar traçar uma rota de construções mais livres para construções mais dependentes do contexto, analisando um continuum que pode sugerir usos mais gramaticalizados dessas construções, conforme análise apresentada nesse artigo. 


\section{Referências}

BYBEE, J.; HOPPER, P. (Org.) Frequency and the emergence of linguistic structure. Amsterdam: John Benjamins, 2001.

BYBEE, J. Language, usage and cognition. Cambridge: Cambridge University Press, 2010.

CAMARA JR., J. Mattoso. História e estrutura da língua portuguesa. Rio de Janeiro: Padrão, 1979.

CROFT, W. Radical construction grammar: syntactic theory in typological perspective. Oxford: Oxford University Press, 2001.

FURTADO DA CUNHA, M. A; OLIVEIRA, M. R; MARTELOTTA, M. E. (Org.). Linguística funcional:teoria e prática. RJ: DP\&A/Faperj, 2003.

GOLDBERG, A. Constructions: a construction approach to argument structure. Chicago: The University of Chicago Press, 1995.

GONÇALVES, S. C. et al.(Org.). Introdução à gramaticalização. São Paulo: Parábola, 2007.

HEINE, B; KUTEVA, T. The genesis of grammar: a reconstruction. Oxford: Oxford University Press, 2007.

HEINE, B; CLAUDI, U; HUENNEMEYER, F. Grammaticalization: a conceptual framework. Chicago: University of Chicago Press, 1991.

HOPPER, P; TRAUGOTT, E. C. Grammaticalization. Cambridge: Cambridge University Press, 1993.

LEHMANN, C. Thoughts on grammaticalization. Munich: Lincom Europa, 1995.

SARAIVA, M. E. F. Construções com objeto incorporado em português: da gramática ao léxico. In: SARAIVA, M. E. F.; MARINHO, J. H. C. Estudos da língua em uso: da gramática ao texto. Belo Horizonte: Ed. UFMG, 2010. p. 43-63.

TRAUGOTT, E. C.; HEINE, B. (Ed.). Approaches to grammaticalization. Amsterdam: John Benjamins, 1991.Vol. 1.

TRAUGOTT, E. C.;DASHER, R. B. Regularity insemantic change. Cambridge: Cambridge University Press, 2005. 
TRAUGOTT, E. C. The concepts of constructional mismatch and typeshifting from the perspective of grammaticalization. Cognitive Linguistics, Berlin, v. 18, n. 4, p. 523-557, 2007.

VOTRE, S.; OLIVEIRA, M. R. Continuidade, variabilidade e mudança na língua portuguesa. Cadernos de Letras da UFF, Niterói, n. 21, p. 121$147,2001$.

Recebido para publicação em 30 de agosto de 2011. Aprovado em 28 de outubro de 2011. 